\title{
Envelhe-sendo na enfermagem: uma abordagem sobre o trabalho do centro de material e esterilização
}

\author{
Aging-being in nursing: an approach on the work of the material and sterilization center \\ Envejecimiento-ser en enfermería: una aproximación al trabajo del centro de material y \\ esterilización
}

Recebido: 20/02/2021 | Revisado: 01/03/2021 | Aceito: 05/03/2021 | Publicado: 14/03/2021

\author{
Alcinéa Rodrigues Athanázio \\ ORCID: https://orcid.org/0000-0002-0520-0007 \\ Universidade Federal Fluminense, Brasil \\ E-mail: alcinea_rodrigues@hotmail.com \\ Enéas Rangel Teixeira \\ ORCID: https://orcid.org/0000-0002-1721-2056 \\ Universidade Federal Fluminense, Brasil \\ E-mail: eneaspsi@hotmail.com \\ Lídia Marina do Carmo Souza \\ ORCID: https://orcid.org/0000- 001-7488-3780 \\ Universidade Federal Fluminense, Brasil \\ E-mail:limarcas@oi.com.br \\ Benedito Carlos Cordeiro \\ ORCID: https://orcid.org/0000-0001-6387-511X \\ Universidade Federal Fluminense, Brasil \\ E-mail: bcordeiro@id.uff.br \\ Rose Mary Costa Rosa Andrade Silva \\ ORCID: https://orcid.org/0000-0002-6403-2349 \\ Universidade Federal Fluminense, Brasil \\ E-mail: roserosa@enf.uff.br \\ Eliane Ramos Pereira \\ ORCID: https://orcid.org/0000-0002-6381-3979 \\ Universidade Federal Fluminense, Brasil \\ E-mail: elianeramos.uff@gmail.com
}

\begin{abstract}
Resumo
Objetivo: conhecer como a equipe de enfermagem, que atua no centro de material e esterilização, percebe o próprio envelhecimento; identificar se a dinâmica do trabalho mostra-se compatível com as atividades realizadas pelos profissionais. Metodologia: Estudo exploratório fundamentado à luz da fenomenologia de Merleau-Ponty e literatura complementar. Utilizou-se a entrevista semiestruturada com 31 profissionais de enfermagem, de um hospital universitário situado no Rio de Janeiro, Brasil. Realizado no período de setembro a novembro de 2014. Resultados: A partir da análise, identificaram-se as categorias: “Aqui”, processo que permeou a alocação no CME; "Agora”, opiniões sobre relações interpessoais e execução do trabalho; "Depois", transitividade comum a vida e designações do trabalho. Conclusão: Ao se sentirem contribuidores ativos inseridos na dinâmica sustentada, graças ao processo de resiliência, não percebem o decaimento da saúde ao processo de envelhecimento, requerendo um olhar cuidadoso na alocação dos recursos humanos.
\end{abstract}

Palavras-chave: Enfermagem; Esterilização; Educação em saúde; Envelhecimento.

\begin{abstract}
Objective: To know how the nursing team, which in the material and sterilization center, perceives aging itself; identify whether the work dynamics is compatible with the activities performed by the professionals. Methodology: Exploratory study based on Merleau-Ponty phenomenology and complementary literature. A semi-structured interview with 31 nursing professionals was used, whose setting was the material and sterilization center of a university hospital in Rio de Janeiro, Brazil. Results: From the analysis, the following categories were identified: "Here", the process that permeated the allocation in the material and sterilization center; "Now", opinions about interpersonal relationships and job performance; "After", common transitivity to life and work designations. Conclusion: When they feel these professionals feel active contributors inserted in the sustained dynamic, thanks to the resilience process, they do not perceive the health decay to the aging process, requiring a careful look at the allocation of human resources.
\end{abstract}

Keywords: Nursing; Sterilization; Education; Health education; Aging. 


\begin{abstract}
Resumen
Objetivo: Conocer cómo el equipo de enfermería, situado en el centro de material y esterilización, percibe el proprio envejecimiento; identificar si la dinámica de trabajo es compatible con las actividades realizadas por los profesionales. Metodología: Estudio exploratorio basado en la fenomenología de Merleau-Ponty y la literatura complementaria. Fue utilizada una entrevista semiestructurada con 31 profesionales de enfermería, cuyo escenario fue el centro de material y esterilización de un hospital universitario ubicado en Rio de Janeiro, Brasil. Realizado de septiembre a noviembre de 2014 a través de dos contactos con el equipo de enfermería. Resultados: A partir del análisis se identificaron las categorías: “Aquí", el proceso que permeó la asignación en el CME; “Ahora”, opiniones sobre relaciones interpersonales y desempeño laboral; "Después", transitividad común a las designaciones de vida y trabajo. Conclusión: Cuando se sienten colaboradores activos insertados en la dinámica sostenida, gracias al proceso de resiliencia, no perciben el deterioro de la salud ante el proceso de envejecimiento, requiriendo una atenta mirada a la asignación de recursos humanos.
\end{abstract}

Palabras clave: Enfermería; Esterilización; Educación; Educación para la salud; Envejecimiento.

\title{
1. Introdução
}

O Centro de Material de Esterilização (CME) é uma unidade funcional, destinada ao processamento de produtos para saúde (Brasil, 2012, Sobecc, 2017). A importância da unidade no controle das infecções hospitalares advém do fato de que, invariavelmente, no âmbito hospitalar, o paciente poderá ser submetido a algum procedimento invasivo e, também, de que a infecção do sítio cirúrgico é apontada como uma das principais complicações, alçando o controle e a prevenção de infecções nosocomiais, ao nível de preocupação mundial (WHO, 2016; Moura, Baylina \& Moreira). Logo, o instrumental a ser utilizado deve apresentar-se livre de contaminação, para que não se torne fonte de transmissão de microrganismos (Ouriques \& Machado, 2013; Gonçalves et al., 2020).

Em sua complexidade, o CME perpassa em muito o trabalho executado por profissionais com maior tempo de serviço e em idade avançada, ainda que requisite profissionais ágeis e qualificados, para corresponder às necessidades de um setor considerado de grande relevância aos procedimentos realizados nos serviços de saúde (Brasil, 2012; Graziano, 2011; Costa, Souza \& Pires, 2016; Athanázio et al., 2019). Dessa situação, apresentou-se o tema: o envelhecimento entre os profissionais da equipe de enfermagem lotados no CME.

O envelhecimento humano - um processo observado em dimensão mundial - reúne a característica de influenciar, simultaneamente, a política, a economia e as relações interpessoais. Em 2003, a Lei 10.741 regulamentou, em todo território nacional, os direitos das pessoas com idade igual ou superior a 60 anos, ao considerá-los legalmente idosos (Alves Júnior, 2011; Brasil, 2013). No entanto, por mostrar-se um processo ativo, o envelhecimento tem revelado que profissionais de 60 anos ou mais encontram-se ainda hígidos para trabalhar, pareados aos mais jovens, conforme ocorre no âmbito de várias profissões, dentre elas, a enfermagem (Silva \& Machado, 2020).

Uma pesquisa que aborda o envelhecimento humano apresenta consonância com a fenomenologia, temporalidade e a pressa em que recai sobre o indivíduo, no processo de envelhecimento ou já idoso, a desaceleração do metabolismo e o decaimento funcional de sistemas e órgãos (Veras \& Oliveira, 2018), e que é observada no âmbito do trabalho no CME. Considerando que a característica humana não é representada somente por sua biologia, o referencial a seguir complementa essas informações.

A filosofia fenomenológica de Merleau-Ponty infere que o corpo não é o mesmo ao que referem as ciências positivas, nosso corpo próprio, tal como o vivenciamos, não é uma coisa, um objeto de estudos das ciências positivas, não é um feixe de ossos, músculos e sangue, não é uma rede de causas e efeitos (Silva, 2009).

Para esse fenomenólogo, o corpo não pode ser considerado pelo aspecto biológico, tendo a fisiologia, anatomia, genética e histologia como únicas abordagens, uma vez que também é dotado de uma interioridade, não explicada somente pela imanência da consciência e nem pela sua exterioridade (Silva, 2009; Daolio, Rigoni \& Roble, 2012). Na concepção fenomenológica da 
percepção, a apreensão dos sentidos ocorre pelo corpo, tratando-se de uma expressão criadora, a partir dos diferentes olhares sobre o mundo, na maior parte das vezes exteriorizados pela fala (Souza, Lima \& Lima, 2014).

Observando o sincronismo entre os conceitos da fenomenologia pontyana aos da atuação em enfermagem, percebe-se que nesse universo o corpo ganha projeção multivalente ao cuidar e ser cuidado. O cuidar é quando o corpo se assume como instrumento do trabalho, atuante nas condições de fragilidade causada pelo sofrimento físico ou psíquico do paciente, que cerceia o encontro com a dor e, não muito raro, com a morte. O ser cuidado é quando, na administração da assistência, encerram-se competências e habilidades, que apesar de contar com a tecnologia pró-saúde, exige o reencontro com o verdadeiro exercício da raça humana: a essência em ser sensível na dispensação de cuidados (Rodrigues, Moraes, Betoschi \& Amaral, 2015).

A temática é relevante sob o ponto de vista institucional, pela possibilidade que apresenta de se repensar o trabalho desenvolvido pela enfermagem no CME, de maneira que o mesmo possa cursar em consonância com a legislação vigente em meio à complexidade que envolve o processamento de instrumentais, dos quais são executados processos considerados da mais alta relevância em tecnologia na área da saúde. O que deu origem à questão: a dinâmica de execução do trabalho no CME, em sua complexidade, passa ilesa ao envelhecimento do trabalhador da enfermagem?

Tendo em vista a dinâmica de execução do trabalho e o envelhecimento do trabalhador da enfermagem do CME, ressaltam-se a importância de aprofundar a discussão e avançar em estudos sobre as questões envolvidas nesse processo. Frente ao exposto, objetivou-se conhecer como a equipe de enfermagem que atua no CME percebe o próprio envelhecimento; identificar se a dinâmica do trabalho se mostra compatível com as atividades realizadas pelos profissionais.

\section{Metodologia}

Trata-se de um estudo exploratório - fenomenológico fundamentado à luz dos conceitos da filosofia da Percepção de Maurice Merleau-Ponty (1908-1961) e da literatura complementar, baseado em dissertação (Athanázio, 2015). Os estudos exploratórios visam proporcionar maior familiaridade com o problema e explicitá-lo (Gil, 2010). Os estudos fenomenológicos constituem-se como a ciência do rigor, que procura observar a experiência humana descrevendo-a tal como ela se mostra (Azevedo \& Lopes, 2010).

A pesquisa foi realizada em um hospital universitário de nível terciário e quaternário, situado na região metropolitana II do Estado do Rio de Janeiro, Brasil e teve como cenário a unidade CME. A amostra foi composta por 31 integrantes da equipe de enfermagem do CME, como enfermeiros, técnicos e auxiliares de enfermagem, distribuídos em plantões do serviço diurnos e noturnos.

Os critérios de inclusão para os participantes foram pertencer ao quadro efetivo da instituição; trabalhar na unidade no mínimo há um ano, período considerado necessário à produção de dados sobre o processo de trabalho e organização no CME. Foram excluídos os profissionais que estiveram ausentes do setor em decorrência de licenças de qualquer natureza, férias ou que se recusaram a participar da pesquisa.

A coleta de dados foi realizada no período de setembro a novembro de 2014 através de dois contatos com a equipe de enfermagem. No primeiro, foi realizado o convite e forneceram-se informações quanto aos propósitos da pesquisa e à importância da sua participação. Posteriormente, foram entregues o Termo de Consentimento Livre e Esclarecido (TCLE) e um questionário para coleta de dados sociodemográficos, como gênero; idade; tempo de serviço na instituição; tempo de serviço no CME; qualificação profissional e nível de formação, assim demonstrados: ensino médio (EM); ensino fundamental (EF); graduação (GR) e pós-graduação (PG).

No segundo encontro, foram recolhidos os documentos assinados e os questionários. Nessa mesma ocasião, foram realizadas as primeiras entrevistas com roteiro semiestruturado. A apresentação dos resultados, a serem discutidos na sequência, partiu de três disparadores: Como é estar e a relação de você existir no CME? Como você percebe o trabalho desenvolvido no 
CME? Você tem oportunidade de apresentar suas ideias ou práticas no cotidiano do trabalho no CME? Ressaltando que esta pesquisa apresenta aderência com a temporalidade e a corporeidade inserida em dado momento, em determinado espaço de tempo e local.

As entrevistas foram realizadas em ambiente reservado, no próprio local de trabalho. As informações empíricas foram registradas em um gravador digital, para posterior transcrição e análise; a duração das oitivas foram 20 minutos em média. Como parâmetro indicador para o encerramento das entrevistas, adotou-se o critério de saturação de respostas, quando as falas dos integrantes se repetem ou deixam de contribuir com novos dados.

Para a organização, categorização e análise dos dados obtidos, realizaram-se leituras e releituras, essa fase constituiuse na exploração das entrevistas, oportunizou conhecer a opinião dos integrantes da equipe de enfermagem do CME e correlacioná-las à filosofia de Merleau-Ponty em associação com o material didático selecionado. O material transcrito contribuiu com a imersão das categorias: "Aqui”; "Agora" e "Depois".

Os aspectos ético-legais transcorreram em conformidade com a pesquisa envolvendo seres humanos, segundo a Resolução vigente do Conselho Nacional de Saúde e o projeto de pesquisa recebeu aprovação do Comitê de Ética em Pesquisa da instituição, parecer $\mathrm{n}^{\circ}$ 777.581. Para preservar o sigilo e a identidade dos participantes foram identificados pela letra $\mathrm{E}$ seguida por numeração arábica entre 01 a 31 (número total de participantes).

\section{Resultados}

A compilação dos dados sociodemográficos demonstrou dentre 31 participantes, 24 (77\%) pertencem ao gênero feminino e 07 (23\%) ao masculino. Com relação à idade, 08 (25\%) se encontram na faixa etária entre 41 e 50 anos; 13 (42\%) entre 51 e 60 anos e 10 (32\%) acima de 60 anos. Quanto ao tempo de atuação laboral na instituição, 09 (29\%) encontram-se entre 10 e 20 anos; 11 (35,4\%) 21 e 30 anos; 09 (29\%) 31 e 40 anos e 02 (6,5\%) acima de 40 anos.

Concernente ao tempo de exercício profissional no CME: 13 (42\%) atuam entre 01 a 04 anos; 12 (39\%) entre 05 a 09 anos; 03 (9\%) 09 a 13 anos e 03 (9\%) acima de 13 anos. Dentre esses, 03 (9\%) são enfermeiros; 16 (52\%) correspondem aos técnicos de enfermagem e 12 (39\%) são auxiliares de enfermagem. No quesito formação profissional: 04 (13\%) tem Graduação; 09 (29\%) Pós-Graduação; 16 (52\%) o Nível Médio; e 02 (6\%) o Ensino Fundamental.

Na etapa referente ao tratamento dos dados, impetrou-se uma leitura exploratória sobre os conteúdos sociodemográficos e informações empíricas, o que permitiu a seguinte interpretação: a equipe de enfermagem que atua no CME é composta por uma equipe predominantemente feminina, em que a maioria são envelhescentes - indivíduos que se encontram no processo de envelhecimento - 51 e 60 anos ( $n=13)$ corresponde a $42 \%$ ou já idosos - categoria a que pertencem os participantes com 60 anos $(n=13)$ ou mais de idade $(32 \%)$.

Um número expressivo de profissionais pesquisados relatou trabalhar na instituição entre 21 e 40 anos. Outro ponto a ser destacado é que a equipe de profissionais lotados no CME atua entre 01 e 04 anos. No quesito formação profissional, a maioria refere ter nível médio, seguido de pós-graduação e graduação, e uma parcela possui ensino fundamental.

A síntese a seguir, pautou-se na confluência entre o material filosófico e, a literatura pesquisada, com a finalidade de dar cunho científico ao material empírico. E, que a partir dos três disparadores já citados, contribuíram para a imersão das categorias "Aqui", "Agora" e "Depois" apresentadas a seguir.

A categoria "Aqui” remete ao processo que permeou a alocação dos profissionais da equipe de enfermagem no CME. Como cheguei aqui?

Nesse sentido perguntou-se: Como é estar e a relação de você existir no CME? Recebendo as seguintes respostas: 
Depois de 27 anos de serviço vim conhecer o trabalho da CME (...) coordeno as atividades e os processos desenvolvidos no setor, estou bem adaptado ao setor e às suas atribuições (09/PG: 51 a 60 anos).

Eu sairia daqui para outro setor (...). Mas não posso mais trabalhar com paciente (23/EM: mais de 60 anos).

Devido à minha limitação, a minha chefia achou que seria um local bom para eu trabalhar. Mas pessoalmente não gosto do setor. Gostaria de estar em outro setor (26/PG: 41 a 50 anos).

Ainda na categoria "Aqui", no que se refere ao estar e existir no CME, é apontada a necessidade de educação permanente.

Deveria haver um maior interesse em estar fazendo uma reciclagem com o pessoal, pois é um setor muito importante (17/EM: mais de 60 anos).

Precisava uma educação continuada para os auxiliares e técnicos e para os enfermeiros também porque quando se fala em educação continuada só se direciona para o auxiliar e o técnico (07/EM: mais de 60 anos).

Tudo que eu posso fazer para resolver os problemas procuro recursos, dentro das minhas condições (10/EM: 41 a 50 anos).

O trabalho é dinâmico, efetivo e todos imbuídos para o mesmo sentido, nos causando, às vezes, impasses devido a uma situação de direcionamento melhor da gerência (28/GR: mais de 60 anos).

Por essas falas, pode ser observado o aspecto que remete à reconstrução do homem junto ao processo de trabalho.

O desgaste originário do trabalho e consequente insatisfação são perceptíveis nestes discursos:

Estou bem aqui, mas insatisfeita com o $n^{\circ}$ insuficiente de funcionários (04/EM: 51 a 60 anos).

Gosto de tudo que eu faço aqui. Enquanto outros não sabem ou não querem fazer e acaba sobrando mais trabalho para mim (05/PG: 41 a 50 anos).

Fora o estresse, gosto muito da equipe. Vim porque estava doente, mas as pessoas colaboram comigo, me ajudam [29/EM: 41 a 50 anos].

Em contraposição aos relatos anteriores, a fala abaixo pode ser percebida como uma autossuficiência sintomática do sofrimento:

Eu me acho bem aqui, estou bem localizada na função que eu sei fazer e faço bem feita. Eu gosto do que faço (07/EM: + de 60 anos).

A seguir, tem-se um discurso que remete a uma reconstrução social pelo aperfeiçoamento imprescindível ao profissional realocado no CME.

Procurei estudar os assuntos pertinentes ao setor, tive uma boa adaptação” (09/PG: 51 a 60 anos).

Os discursos seguintes exaltam a necessidade humana de agregação:

Gosto dos meus colegas, mas, na verdade, gosto mesmo é de trabalhar com o paciente, mas estou sem condições devido à idade já avançada e também por apresentar problemas de saúde (12/EF: + de 60 anos).

Eu acho maravilhoso o setor, gosto daqui, me relaciono bem com os meus colegas (16/EM: 51 a 60 anos).

Eu gosto de estar no CME, me sinto bem e procuro estar bem com todos (17/EM: + de 60 anos).

Para alguns, a transferência para o CME, por motivo de relocação de material humano ou de doença, desperta insatisfação. No entanto, para outros, embora sentindo falta do contato com o paciente, constitui-se oportunidade de adaptação.

Por fim, ressaltando-se como um dado importante acerca da percepção do envelhecimento que aparece na fala do participante 12/EF de mais de 60 anos, citada acima, em determinada parte: 
gosto mesmo é de trabalhar com o paciente, mas estou sem condições devido à idade já avançada e também por apresentar problemas de saúde.

Percebe-se que apesar do papel estratégico na qualidade da esterilização do material destinado ao processo assistencial nos serviços de saúde, frequentemente, o CME conta com número reduzido de funcionários ou sem a qualificação desejada para o desenvolvimento das tarefas.

A categoria "Agora" busca inteirar-se das opiniões dos participantes sobre as relações interpessoais e a execução do trabalho no CME.

Uma vez aqui, o que penso agora que trabalho no CME?

Trata-se de uma realidade, no cotidiano dos participantes, a execução das atribuições profissionais no CME e, como a maioria desses, à época da pesquisa, encontrava-se na faixa etária entre 51 a 60 anos ou mais de idade, perguntou-se: Como você percebe o trabalho desenvolvido no CME?

É um trabalho de suma importância, porque esse setor é o coração do hospital (10/EM: 41 a 50 anos). o trabalho é repetitivo, estressante, bastante estressante, sem criatividade. Eu gostaria de alguma coisa que desse mais vida ao nosso trabalho, mais alma (01/EM: mais de 50 anos).

O trabalho desenvolvido aqui é muito importante, apesar de não trabalhar direto com o paciente, mas sei que tudo que é feito aqui é direcionado para todos os setores e está relacionado ao paciente (02/PG: + de 50 anos).

É muito importante, aqui é o coração do hospital (27/EF: mais de 60 anos).

Os discursos externam a consciência sobre a relevância dessa unidade no contexto das instituições de saúde, em contrapartida, relacionaram a doença ou a limitação como um estigma do CME:

O CME tem que funcionar a pleno vapor, tolerância, personalidade, sem pessoas com deficiência $(25 / E M:+$ de 60 anos).

Trabalhamos com equipamentos caríssimos e muito diversificados de material, tem que estar atento e ter muita colaboração. E só mandam para cá pessoas doentes, limitadas e sem condições para o serviço. Na realidade, se tem poucas condições para que o CME funcione bem (10/EM: 41 a 50 anos).

Considerando os discursos acima, a recusa ou a negação podem ser concebidas como um processo protetivo ou de defesa, reversível pela aceitação que surge com o tempo, nesse eixo dentre outros podemos citar o envelhecimento ou a doença.

A categoria "Depois" refere-se à transitividade comum à vida das pessoas e as designações do trabalho, assim, alguns participantes manifestaram interesse em oferecer uma contribuição ao setor.

Os profissionais de enfermagem no desenvolvimento de suas atividades estão frente às novas tecnologias em esterilização e processamento de materiais que possibilitam melhor qualidade de vida ao usuário, a refletir na assistência prestada nos serviços de saúde.

Como posso contribuir com o trabalho no CME?

Nesse sentido, ao perguntar-se: Você tem oportunidade de apresentar suas ideias ou práticas no cotidiano do trabalho em $C M E$ ? Retornaram as seguintes respostas:

Nem todos os colegas são abertos para ouvir, têm mais resistência para ouvir. O novo assusta (02/PG: 51 a 60 anos). Diagnosticamos os problemas e as soluções que são apresentadas não são levadas em conta, deixando um pouco de frustração (09/PG: 51 a 60 anos).

Ninguém tem oportunidade de expressar ideias e, quando chega a fazê-la, termina em confusão, em desavença, em atrito ou passando ser melhor que o outro, simplesmente ignorado (10/EM: 41 a 50 anos).

As ideias não aceitam, porque não vai depender dos colegas, tem que passar primeiro pela coordenadora e chefia imediata; não tem como desenvolver nada (19/EM: 51 a 60 anos). 


\section{Discussão}

Na visão de Merleau-Ponty, não há um lugar da verdade (...), a verdade passa pelos outros. Ou procuramos a verdade com eles, ou não a descobriremos (Merleau-Ponty, 2015).

Nos discursos, evidenciou-se que um participante relatou adaptação integral ao CME, sendo que, entre os demais, percebeu-se adesão com ressalvas ou explicitação direta de insatisfação com o referido setor. Dentre eles, foi observada, embora não tão diretamente, a presença da percepção do processo de envelhecimento.

A ausência de condições favorecedoras de um ambiente de trabalho que proporcione satisfação e bem-estar aos trabalhadores altera o produto final da assistência direta ou indireta ao paciente (Spagnol et al., 2015; Borgheti, Viegas \& Caregnato, 2016). A palavra é gesto e solicita ao corpo atenção da existência inteira, porque expressa uma intencionalidade e uma significação (Terra, Gonçalves, Santos \& Erdmann, 2009).

O trabalho em si não é nocivo e perigoso, mas sim, as consequências deletérias que sobrevêm pela forma com que ele é organizado pelo próprio homem (Neis, Gelbcke, Salum \& Oliveira, 2012). A organização do trabalho determina não somente a divisão de atribuições, mas também, a divisão das pessoas, angariando grande influência na saúde dos trabalhadores, principalmente no que se refere à carga psíquica do trabalho (Martins, Robazzi \& Bobroff , 2010).

É função do enfermeiro educar e capacitar os profissionais que integram o serviço de saúde, principalmente os responsáveis pelos procedimentos de limpeza e desinfecção, com o intuito de barrar a cadeia de transmissão de microrganismos patógenos, ao diminuir o risco de infecção hospitalar e melhorar a qualidade da assistência (Neis, Gelbcke, Salum \& Oliveira, 2012). O enfermeiro no CME age como agente educador, agregando conhecimentos no cotidiano do trabalho, com qualidade, visando à segurança do paciente (Mattos, 2016; Athanázio, 2015; Bugs et al., 2017).

$\mathrm{O}$ excesso de normas, rotinas e exigências em um ambiente laboral impede o trabalhador de se transformar e recriar seu trabalho resultando no estresse laboral (Spagnol et al., 2015). O estresse ocupacional, compreendido como complexo processo em que o trabalhador busca responder a demandas que ultrapassam as possibilidades de adaptação individual e social, desencadeando-se transtornos no plano biológico e/ou comportamental (Sousa \& Araújo, 2015).

O trabalho desenvolvido pela equipe de enfermagem é gerador de sentimentos ambíguos, ora ele pode colaborar para vivências de prazer ora para vivências de sofrimento. Por ser gerador de sentimentos ambíguos, o trabalho também proporciona vivências de prazer, pois é por meio dele que o ser humano constrói sua vida e se insere no mundo laboral, não somente como forma de sobrevivência, mas também, para realização pessoal e profissional (Martins, Robazzi \& Bobroff , 2010). Ao contrário da vida de pessoas envelhescentes ou envelhecidas, os valores agregados ao trabalho, embora importantes à autonomia global do indivíduo, mostram-se secundários, por oportunizarem a expressão da afetividade humana e a efetividade laboral.

O outro faz parte de meu corpo, não está em mim nem fora. Ele está na frente, ao lado e atrás; faz parte de meu sentir e, assim como eu, ele faz uma extensão com o mundo (Terra, Gonçalves, Santos \& Erdmann, 2009). O companheirismo e as relações de afeto entre colegas de trabalho auxiliam a diminuir o impacto causado pelas altas demandas psicológicas inerentes ao contexto ocupacional, amortecendo o estresse (Sousa \& Araújo, 2015).

$\mathrm{O}$ trabalho fragmentado que a enfermagem realiza segue os princípios taylorizados, e, em referência às atividades desenvolvidas no CME, tem como objeto de trabalho materiais processados para a saúde, ao garantir a quantidade e qualidade necessárias para uma assistência segura aos usuários dos serviços de saúde (Spagnol et al., 2015). Episódios de enxaqueca, estresse, irritação, desgaste físico, depressão, dores, varizes, lesões por esforços repetitivos e doenças osteomusculares, hipertensão, fadiga, acidentes são alguns dos agravos que podem ser associados a situações de risco ocupacional (Espíndola \& Fontana, 2012). O homem natural segura as duas pontas da corrente, pensa ao mesmo tempo em que sua percepção penetra nas coisas que faz aquém do seu corpo (Merleau-Ponty, 2015). 
O envelhecimento, tal qual a saúde, é um processo silencioso; nós não os percebemos na sua plenitude. Na maior parte das vezes, apenas os identificamos quando adoecemos (Rodrigues \& Brêtas, 2015). Conforme Merleau-Ponty, a recusa da deficiência é apenas o avesso de nossa inerência a um mundo, a negação implícita daquilo que se opõe ao movimento natural que nos lança a nossas tarefas, preocupações, situação, a nossos horizontes familiares (Merleau-Ponty, 2015).

Mediante aos discursos, a recusa ou a negação podem ser concebidas como um processo protetivo ou de defesa, reversível pela aceitação que surge com o tempo. Nesse eixo, dentre outros, podemos citar o envelhecimento ou a doença.

A percepção - sob o ponto de vista da filosofia pontyana - decorre de uma síntese presuntiva ou síntese de horizontes que integra uma experiência de campo, cujas essências consistiriam apenas no movimento das vivências através de uma estrutura de horizontes ou estrutura da figura-fundo (Terra, Gonçalves, Santos \& Erdmann, 2009).

Parafraseando o fenomenólogo, como figuras-fundo sob a égide do "portal" CME, os trabalhadores tendem a experienciar o sentimento de invisibilidade, permeado por um imaginário de que o cuidado indireto é menos valorizado que o cuidado direto ao cliente, embora o discurso de que o primeiro instrumentaliza a prestação do segundo. Esse sentimento do trabalhador está presente como um dos aspectos encontrados na equipe do CME (Merleau-Ponty, 2015).

Por tratar-se de um processo dinâmico em que as influências do ambiente e do indivíduo interagem reciprocamente, permitindo a adaptação, apesar da presença de estressores, a resiliência tende a contribuir com a superação de situações de risco e assegurar a continuidade de um desenvolvimento saudável (Sousa \& Araújo, 2015). Mediante ao advento de novas tecnologias em diagnósticos e tratamentos, surgem novos equipamentos e para atender a essa complexidade, os profissionais do CME, precisam adaptar-se se reorganizando de forma a atender as exigências necessárias (Athanázio, et al., 2019)

Ao propiciar-se um espaço de compartilhamento de sentimentos aos trabalhadores, pode-se estabelecer uma linguagem que leve a uma nova inteligibilidade, novo sentido para o trabalho, com efeito positivo no processo das relações de cooperação e de troca de conhecimentos, que, repercutem nos sentimentos de prazer dos indivíduos ao desenvolver suas atividades Algumas demandas quando exteriorizadas pela via física, são tratadas com facilidade, enquanto que outras responsáveis por levar a sobrecarga mental e ao desempenho diminuído, podem ser consideradas como inaptidão do indivíduo frente aos desafios e cobranças inerentes ao desenvolvimento do trabalho ((Martins, Robazzi \& Bobroff, 2010).

Desse modo, os profissionais quando associam a transferência da assistência direta para a indireta no CME, por motivo de doença e, ao se preocuparem em dar sugestões para o melhor desenvolvimento do trabalho, nesse setor, como forma de melhor adaptação ao ambiente, podem não estar se atentando das sutis alterações fisiológicas proporcionadas pelo processo de envelhecimento. $\mathrm{O}$ ambiente frenético do CME reúne características capazes de deflagrar ou até mesmo de potencializar essas consequências, por requisitar esforço de estruturas cruciais no processo de envelhecimento, dentre elas, o sistema musculoesquelético, principal local de transformação e armazenamento de energia.

Nesse contexto, com a intenção de atribuir significados positivos aos fenômenos captados do cenário laboral pelo corpo trabalhador, os participantes assistiram suas aspirações colaborativas de sujeitos, inseridos num mundo de interações, serem rejeitadas, enquanto, com muito esforço, em seus processos de resiliência, submetiam-se a riscos, envelhe-sendo na enfermagem no CME.

\section{Considerações finais}

Trazendo as interpretações da fenomenologia pontyana da percepção para a realidade da enfermagem no CME, esse setor imprime uma alegoria em forma de moldura que resguarda do exterior seus trabalhadores, em sua maioria, mulheres envelhescente, em processo de envelhecimento ou já envelhecidas, que prestam cuidados indiretos no anonimato, devido características físicas do CME corresponder a de um ambiente confinado. 
A dinâmica do trabalho executado, na análise do material pesquisado, mostrou-se compatível com as contribuições da equipe de enfermagem, graças ao processo de resiliência, cujo modus operandi foi oferecer sugestões não aceitas para uma melhor adaptação ao ambiente, o que viria a repercutir na disponibilização de estruturas internas dos profissionais, no enfrentamento da baixa autoestima laboral e do sentimento de menos valia. Segundo os participantes, a relocação no CME, se deu por necessidade do serviço ou por limitação, doença, não apresentando conotações com o envelhecimento.

Embora a dinâmica do trabalho no CME mostra-se compatível com as atividades dos profissionais, evidenciou-se, nesta pesquisa, a necessidade do cuidado, na divisão de tarefas, ao se alocar recursos humanos de forma compatível a cada profissional. Os participantes não relacionam o decaimento da saúde ao processo de envelhecimento, acelerado pelas condições de trabalho, uma vez que não percebem a sua própria condição pessoal, ainda que se sintam contribuidores ativos em suas funções.

Destaca-se como limitação do estudo a constituição da amostra somente por profissionais de enfermagem de um hospital público, requisitando a realização de outras pesquisas e discussões sobre a temática que envolvam o envelhe-sendo na enfermagem e o trabalho no $\mathrm{CME}$, buscando contribuir com a autoestima profissional, dar maior visibilidade à unidade e aos trabalhadores da enfermagem que lá atuam.

\section{Agradecimentos}

Aos profissionais de enfermagem do Centro de Material e Esterilização que contribuíram para a realização da pesquisa.

Este estudo foi baseado na dissertação intitulada "Educação Permanente a trabalhadores do Centro de material e Esterilização: uma contribuição da enfermagem"apresentada em 2015 ao Curso de Mestrado Profissional em Ensino na Saúde da Escola de Enfermagem Aurora de Afonso Costa, Universidade Federal Fluminense, Rio de Janeiro/Brasil.

\section{Referências}

Alves Júnior, E. D. (2011). A Pastoral do Envelhecimento Ativo. Apicuri.

Athanázio, A. R. (2015). Educação Permanente a trabalhadores do Centro de Material e Esterilização: uma contribuição da enfermagem. [Dissertação]: Universidade Federal Fluminense

Athanázio, A. R., Teixeira, E. R., Cordeiro, B. C., Souza, L. M. C., Pereira, E. R., \& Silva, R. M. C. R. A. (2019). Aquisição de novos saberes pela equipe de enfermagem do centro de material e esterilização. In book: Discursos, Saberes e Práticas da Enfermagem; pp.107-15. Ed Atena. 10.22533/at.ed.75519261212

Azevedo, R. F., \& Lopes, R. L. M. (2010). Concepção de corpo em Merleau-Ponty e mulheres mastectomizadas. Rev. bras. enferm; 63(6), 1067-70. https://dx.doi.org/10.1590/S0034-71672010000600031

Borgheti, S. P., Viegas, K., \& Caregnato, R. C. A. (2016). Biossegurança no centro de materiais e esterilização: dúvidas dos profissionais. Revista SOBECC, 219(1), 3-12. https://doi.org/10.5327/Z1414-4425201600010002

Bugs, T. V., Rigo, D. F. H., Bohrer, C. D., Borges, F., Marques, L. G. S., Vasconcelos, R. O., \& Alves, D. C. I. (2017). Profile of the nursing staff and perceptions of the work performed in a materials center. http://www.dx.doi.org/10.5935/1415-2762.20170006

Costa, C. C. P., Souza, N. V. D. O., \& Pires, A. S. (2016). Perfil dos trabalhadores de uma central de material e esterilização: uma análise das características sócio profissionais. 10.9789/2175-5361.2016.v8i1.3633-3645

Daolio, J., Rigoni, A. C. C., \& Roble, O. J. (2012). Corporeidade: o legado de Marcel Mauss e Maurice Merleau-Ponty. Pro-Posições. Campinas. 23(69): 17993. https://dx.doi.org/10.1590/S0103-73072012000300011

Espíndola, M. C. G., \& Fontana, R. T. (2012). Riscos ocupacionais e mecanismos de autocuidado do trabalhador de um centro de material e esterilização. Rev. Gaúcha Enferm; 33 (1), 116-23

Gil, A. C. (2010). Como elaborar projetos de pesquisa: Atlas

Gonçalves, R. C. da S., Sé, A. C. S., Pezzi, M. da C. S., Pinto, C. M. I., Souza, P. A., Fernández, B. M., Hernández, P. E., \& Tonini, T. (2020). Nursing activities for the diagnosis "Risk for contamination of medical devices". Research, Society and Development, 9(9), e683997794. https://doi.org/10.33448/rsd-v9i9.7794

Graziano, K. U., Silva, A., \& Psaltikids, E. M. (2011). Enfermagem em Centro de Material e Esterilização. Manole.

Martins, J. T., Robazzi, M. L. C. C., \& Bobroff, M. C. C. (2010). Pleasure and suffering in the nursing group: reflection to the light of Dejour psychodynamics. Rev. esc. Enferm. USP; 44(4), 1107-11 
Research, Society and Development, v. 10, n. 3, e23710313151, 2021

(CC BY 4.0) | ISSN 2525-3409 | DOI: http://dx.doi.org/10.33448/rsd-v10i3.13151

Merleau-Ponty, M. (2015). Fenomenologia da percepção. Martins Fontes.

Ministério da Saúde, Brasil. (2013). Estatuto do Idoso, (3a ed.). https://bvsms.saude.gov.br/bvs/publicacoes/estatuto_idoso_3edicao.pdf

Ministério da Saúde, Brasil. (2012). Agência Nacional de Vigilância Sanitária (ANVISA). Resolução - RDC nº 15, de 15 de março de 2012. Diário Oficial da União (DOU) nº 54, de 19 de março de 2012 - Seção 1 - pag. 43-6.

Moura, J., Baylina, P., \& Moreira, P. (2018). Exploring the real costs of healthcare-associated infections: an international review. Int J Healthc Manag. 11(4):33340. http://dx.doi.org/10.1080/20479700.2017.1330729

Neis, M. E. B., Gelbcke, F. L., Salum, N. C., \& Oliveira, T. T. (2012). Centro de material e esterilização: estudo do tempo efetivo de trabalho para dimensionamento de pessoal. Rev. Eletr. Enf. 13(3):422-30

Ouriques, C. M., \& Machado, M. E. (2013). Enfermagem no Processo de Esterilização de Materiais. Texto Contexto Enferm; 22(3): 695-03. https://doi.org/10.1590/S0104-07072013000300016

Rodrigues, L. A., Moraes, E. L., Betoschi, J. R., \& Amaral, C. P. (2015). Como a dor e o sofrimento do paciente oncológico afetam o médico no processo de tratamento. CuidArt Enferm; 9(1):58-70

Rodrigues, M. R., \& Brêtas, A. C. P. (2015). O Envelhecimento no Trabalho na Perspectiva de Trabalhadores da Área de Enfermagem. Trab. educ. Saúde; 13(2): $343-60$

Silva, M. C. N., \& Machado, M. H. (2020). Sistema de Saúde e Trabalho: desafios para a Enfermagem no Brasil. Ciênc. saúde coletiva; 25 (1), 7-13. Rio de Janeiro. https://doi.org/10.1590/1413-81232020251.27572019

Silva, R. M. C. R. A. (2009). Conceito de Corpo em Merleau-Ponty como tentativa de superação ao dualismo psicofísico. In: Teixeira ER, \& colaboradores. Psicossomática no Cuidado em Saúde. Atitude Transdisciplinar. Yendis; p.31-65.

Sociedade Brasileira de Enfermagem em Centro Cirúrgico, Recuperação Anestésica e Centro de Material e Esterilização. (2017). Práticas recomendadas SOBECC. (7 $7^{\mathrm{a}}$ ed.) São Paulo

Souza, L. M. C., Lima, I. B., \& Lima, J. W. P. (2014). Cuidados paliativos em enfermagem. In: Associação Brasileira de Enfermagem; Bresciani, H. R., Martini, J. G., Mai, L. D, organizadores. PROENF. Programa de Atualização em Enfermagem: Saúde do Adulto; Ciclo 9. Porto Alegre; Artmed Panamericana. (Sistema de Educação Continuada a Distância, v.3)

Sousa, V. F. S., \& Araújo, T. C. C. F. (2015). Occupational Stress and Resilience Among Health Professionals. Psicol. cienc. prof. 35 (3), pp.900-15. ISSN 1414-9893. http://dx.doi.org/10.1590/1982-370300452014

Spagnol, C. A., Colem, N. C. S., Oliveira, B. K. S., Pereira, A. D. S., Silva, R. H. L., Mussel, I., Santos, R., Manoel, V., Figueiredo, P., \& Moreira, A. (2015). Escalda-Pés: Cuidando da enfermagem no Centro de material e esterilização. Rev. SOBECC; 20(1): 45-2. https://revista.sobecc.org.br/sobecc/article/view/79

Terra, M. G., Gonçalves, L. H. T., Santos, E. K. A., \& Erdmann, A. L. (2009). Fenomenologia de Maurice Merleau-Ponty como referencial teórico-filosófico numa pesquisa de ensino em enferrnagem. Rev Gaucha Enferm, 30(3):547-51

Veras, R. P., \& Oliveira, M. (2018). Envelhecer no Brasil: a construção de um modelo de cuidado. Cien Saude Colet. 23(6):1929-36. https://doi.org/10.1590/1413-81232018236.04722018

World Health Organization and Pan American Health Organization. (2016). Decontamination and reprocessing of medical devices for health-care facilities Geneva: WHO/PAHO. http://apps.who.int/iris/bitstream/handle/10665/250232/9789241549851-eng.pdf;jsessionid=034E349F27874D382B05849382 C38500? sequence $=1$ 